\title{
La otitis media infantil tiene un elevado componente hereditario
}

The heritability of otitis media. A twin and triplet study.

Casselbrant ML, Mandel EM, Fall PA et al. JAMA 1999;282:2125-2130

\section{Objetivo}

Determinar un posible componente genético en la frecuencia y duración de episodios de derrame en oído medio y otitis media aguda en niños de 1 y 2 años de edad.

\section{Diseño}

Estudio prospectivo de cohorte de gemelos dobles (GD) y triples (GT) entre 1982 y 1995, durante 102 años.

\section{Lugar}

Centro universitario (Pittsburgh) de investigación de 0titis Media. Pennsylvania, EEUU.

\section{Participantes}

Participaron 168 grupos de GD y 7 de GT de igual sexo, de un total de 900 GD y 108 GT reclutados durante los primeros 2 meses de vida.

\begin{abstract}
Resultados
De los 140 grupos de GD o GT cuyo tipo zigótico pudo verificarse, $138(99 \%)$ fueron seguidos durante un año y $126(90 \%)$ hasta los 2 años. Al cabo de 2 años, el tiempo de duración del derrame en el oído medio tuvo un patrón hereditario estimado de $0,73, p<0,001$ (73\% de la variabilidad de aparición o no de efusiones en oído medio podría explicarse por la herencia). La discordancia para 3 o más episodios de derrame fue menor para gemelos monozigóticos (GMZ) que para dizigọ́ticos $(\mathrm{GDZ})$ (0,04 vs 0,37 respectivamente, $p=$ $0,01)$; la discordancia para un episodio de OMA fue 0,04 en GMZ vs 0,49 en $\operatorname{GMZ}(p=0,005)$.
\end{abstract}

\section{Conclusiones}

El estudio sugiere un componente genético intenso en la duración del derrame en oído medio y en episodios de otitis media en los niños.

\section{Medición de resultados principales}

Proporción de tiempo con derrame en oído medio, episodios de derrame, y episodios de otitis media aguda (0MA), según tipo zigótico.

Fuente de financiamiento: Subsidios del National. Institute on Deafness and Other Communication Disorders, NIH, Bethesda, MD, EEUU

\section{COMENTARIO}

El método de estudiar grupos de GD o GT para cuantificar los componentes hereditarios y ambientales en la determinación de rasgos humanos (patológicos o no), es conocido desde los principios del siglo 20 y se lo ha utilizado para innumerables enfermedades, defectos o malformaciones. ${ }^{1}$ En términos simples, se suele usar la concordancia o discordancia entre los dos gemelos de un par, para el rasgo o característica bajo estudio; si uno lo presenta y el otro no, son discordantes; si ambos lo presentan, son concordantes. Se comparan Los resultados entre GMZ y GDZ. Si el rasgo tiene un componente hereditario elevado, la concordancia para el mismo es mucho mayor entre los $M Z$ que entre los $D Z$, por compartir aquéllos el $100 \%$ de sus genes mientras que los DZ comparten sólo el $50 \%$. Si un rasgo tiene el $100 \%(1,0)$ de "heredabilidad", significa que el ambiente no tiene ninguna influencia, la discordancia entre gemelos MZ será 0 y entre los DZ será 0,5. Los autores del trabajo utilizaron técnicas diagnósticas otológicas complejas, métodos avanzados para verificar el tipo zigótico (polimorfismos de grupos sanguíneos o de ADN microsatelital), y un método estadístico sofisticado de análisis de regresión múltiple publicado por autores reconocidos (JC DeFries y colaboradores). Los resultados y conclusiones del estudio no son demasiado sorprendentes, dado que existe una amplia bibliografía (citada por los autores) sobre variaciones anatómicas del oído medio, trompa de Eustaquio y apófisis mastoide en diversas poblaciones humanas (por ejemplo, los indígenas de la etnia Apache). ${ }^{2}$ Lamentablemente los autores no proporcionan información sobre el origen étnico de sus participantes. "Heredabilidad" no significa "\% de susceptibilidad" (a la OMA o duración del derrame). La definición de "heredabilidad" en realidad significa "la proporción de la varianza* fenotípica atribuída a varianza genética". Es decir, no es el porcentaje del rasgo medido en sí, sino el porcentaje de su variación lo que se está midiendo. Si tengo un par de hijos gemelos, y uno tiene otitis aguda, el riesgo para el otro de también tenerla sería elevado (>90\%) si son GMZ, y menor (cerca del $50 \%$ ) si son GDZ. Pero no puedo decir que "su susceptibilidad a la otitis se debe en un $73 \%$ a sus genes y un $27 \%$ al ambiente". Además, cuando ambos comparten el mismo ambiente, es muy difícil deslindar un efecto ambiental oculto. ${ }^{3}$ 0tro dato que sería de interés es saber cómo fueron seleccionados los 168 grupos de GD y los 7 grupos de GT (del mismo sexo) de los 900 de GD y 108 de GT registrados en el hospital durante el periodo de estudio. (Los GDZ de sexo discordante suelen ser aproximadamente un tercio del total). Si fuese más probable, en una institución altamente especializada, que hayan consultado las familias con dos hijos afectados, que las que tenían sólo uno, entonces pudo haber habido una proporción de concordancia falsamente elevada, es decir, un sesgo de identificación* ("ascertainment bias"). La implicancia clínica del estudio es clara: Frente a un caso de otitis media aguda (o simple derrame de oído medio) es recomendable examinar a su(s) hermano/a(s), por el alto riesgo de que también la padezca. La concordancia de cerca del $50 \%$ (posiblemente algo excesiva por sesgo de identificación) para los GDZ y también es aplicable para los hermanos no gemelos (en este caso, menores de 2 años).

*Ver glosario

\section{Dr. Martín Roubicek}

Profesor titular, cátedra de Genética General, Facultad de Ciencias Exactas y Naturales, UNMP

Especialista en Genética Humana y en Endocrinología, Pcia. Bs.As.

Jefe del Servicio de Endocrinología, Hospital Privado de Comunidad, Mar del Plata.

\section{Referencias}

1. Vogel F, Motulsky AG. Human Genetics. Problems and Approaches. 3rd ed. Springer, Berlin 1997: 228-240

2. Ehrlich GD, Post JC. Susceptibility to otitis media. Strong evidence that genetics plays a role. Editorial. JAMA 1999;282:2167-2169

3. Suzuki DT, Griffiths AJF, Miller H, Lewontin R. An Introduction to Genetic Analysis. 4th ed. W.H.Freeman, New York 1989: 654-655 